\title{
Seismic performance of a load-bearing prefabricated composite wall panel structure for residential construction
}

\begin{tabular}{|c|c|}
\hline Journal: & Advances in Structural Engineering \\
\hline Manuscript ID & ASE-19-0787.R1 \\
\hline Manuscript Type: & Original Research \\
\hline $\begin{array}{r}\text { Date Submitted by the } \\
\text { Author: }\end{array}$ & $11-$ Feb-2020 \\
\hline Complete List of Authors: & $\begin{array}{l}\text { Huang, Qunyi; Southwest Jiaotong University, School of Civil Engineering } \\
\text { Orr, John; University of Cambridge, Department of Engineering } \\
\text { Huang, Yanxia; Anyang Institute of Technology, School of Civil and } \\
\text { Architectural Engineering } \\
\text { Xiong, Feng; Sichuan University, College of Architecture \& Environment; } \\
\text { Sichuan University, MOE Key Laboratory of Deep Underground Science } \\
\text { and Engineering } \\
\text { Jia, Hongyu; Southwest Jiaotong University, School of Civil Engineering }\end{array}$ \\
\hline Keywords: & $\begin{array}{l}\text { Prefabrication, Composite panels, Quasi-static testing, Seismic } \\
\text { performance, Residential construction }\end{array}$ \\
\hline Abstract: & $\begin{array}{l}\text { To improve both seismic performance and thermal insulation of low-rise } \\
\text { housing in rural areas of China, the present study proposes a new type } \\
\text { of building structure that achieves appropriate seismic performance and } \\
\text { energy efficiency using field-assembled load-bearing prefabricated } \\
\text { composite wall panels (LPCP). A } 1: 2 \text { scale prototype built using LPCP is } \\
\text { subjected to quasi-static testing so as to obtain damage characteristics, } \\
\text { load-bearing capacity, and load-displacement curves in response to a } \\
\text { simulated earthquake. As a result, seismic performance indicators of } \\
\text { load-bearing capacity, deformation, and energy-dissipating } \\
\text { characteristics, are assessed against the corresponding seismic design } \\
\text { requirements for rural building structures of China. Experimental results } \\
\text { indicate that the earthquake-resistant capacity of the prototype is } 68 \% \\
\text { higher than the design value. The sample has a ductility factor of } 4.7 \text {, } \\
\text { which meets the seismic performance requirement mandating that the } \\
\text { ductility factor of such concrete structures should exceed } 3 \text {. The design } \\
\text { can be further optimized to save the consumption of material. This } \\
\text { shows that the LPCP structure developed here has decent load-bearing } \\
\text { capacity, ductility and energy dissipation abilities, a combination of which } \\
\text { is in line with the earth quake specifications. A new construction process } \\
\text { proposed here based on factory prefabrication and field assembly leads } \\
\text { to a considerable reduction of energy consumption. }\end{array}$ \\
\hline
\end{tabular}

\section{SCHOLARONE" Manuscripts}




\title{
Seismic performance of a load-bearing prefabricated composite
}

\section{wall panel structure for residential construction}

\author{
QunyiHuanga,b, John Orrc, YanxiaHuangd,,*, Feng Xiong ${ }^{\mathrm{b}}$, HongyuJia $^{\mathrm{a}}$
}

\section{Abstract}

To improve both seismic performance and thermal insulation of low-rise housing in rural areas of China, the present study proposes a new type of building structure that achieves appropriate seismic performance and energy efficiency using field-assembled load-bearing prefabricated composite wall panels (LPCP). A 1:2 scale prototype built using LPCP is subjected to quasi-static testing so as to obtain damage characteristics, load-bearing capacity, and load-displacement curves in response to a simulated earthquake. As a result, seismic performance indicators of load-bearing capacity, deformation, and energy-dissipating characteristics, are assessed against the corresponding seismic design requirements for rural building structures of China. Experimental results indicate that the earthquake-resistant capacity of the prototype is $68 \%$ higher than the design value. The sample has a ductility factor of 4.7, which meets the seismic performance requirement mandating that the ductility factor of such concrete structures should exceed 3 . The design can be further optimized to save the consumption of material. This shows that the LPCP structure developed here has decent loadbearing capacity, ductility and energy dissipation abilities, a combination of which is in line with the earth quake specifications. A new construction process proposed here based on factory prefabrication and field assembly leads to a considerable reduction of energy consumption.

Key words: Prefabrication; Composite panels; Quasi-static testing; Seismic performance; Residential construction

\footnotetext{
${ }^{1}$ School of Civil Engineering, Southwest Jiaotong University, Chengdu, China;

${ }^{2}$ College of Architecture and Environment, Sichuan University, Chengdu, China;

${ }^{3}$ Department of Engineering, University of Cambridge, Trumpington Street, Cambridge, UK;

${ }^{4}$ School of Civil and Architectural Engineering, Anyang institute of Technology, Anyang, China

\section{Corresponding author}

Yanxia Huang, School of Civil and Architectural Engineering, Anyang institute of Technology,West section of Huanghe Avenue, Anyang 45000, China Email: huangyanxia0301@hotmail.com
} 


\section{Introduction}

Located between the circum-Pacific earthquake zone and the Euro-Asian earthquake zone, China is one of the most earthquake-prone countries in the world. A review of historical data reveals that earthquakes in China are mostly characterized by high frequency, shallow hypocentres, great intensity, and wide distribution(Huang et al,2014; Jia et al 2013). Since the Tang Shan earthquake in 1976, a multitude of destructive earthquakes took place in China, with the majority of which occurring in broad and densely populated rural areas(Tian et al, 2006). Most rural building structures in China are self-built, primarily in masonry, brick, or wood, and often exhibit poor seismic performance. During the 2008 Great Wenchuan earthquake (8.0 Ms), such rural buildings were subject to severe damage or even total collapse.

The sintering of clay to make solid bricks for rural buildings consumes large amount of coal, with associated $\mathrm{CO} 2$ emissions, and the manufacturing process emits significant amount of dust, which can lead to severe environmental pollution(Cao et al, 2015). According to $\mathrm{Ji}(2018), 1770-2077 \mathrm{~kg}$ of coal are needed to produce 10,000 solid bricks in China. Such issues are barriers to the promotion of energy conservation technology in rural building structures. Therefore, there exists an urgent need to develop an integrated technology that can simultaneously enhance the seismic performance and energy efficiency of rural building structures.

To enhance the seismic performance and energy efficiency of rural building structure, this paper details the development of the Load-bearing Prefabricated Composite wall Panel (LPCP) to serve as the primary load-bearing and thermal insulation component for establishing the rural building structure with appropriate seismic performance and energy efficiency based on factory prefabrication and field assembly. The proposed LPCP is a sandwich construction, with a central thermal insulation layer enclosed between two steel mesh reinforced concrete layers. 
56 The reinforced concrete layers are connected through an array of two-way diagonal reinforcing 57 bars so as to form a steel-mesh-reinforced concrete composite plate (Fig. 1). The insulation 58 thickness can be adjusted in accordance with the regional climate condition and energy 59 efficiency requirements. The strength, spacing and diameter of the reinforcing bars in the 60 reinforcement mesh as well as the strength and thickness of the concrete layers is determined 61 based on structural calculations.

62 63

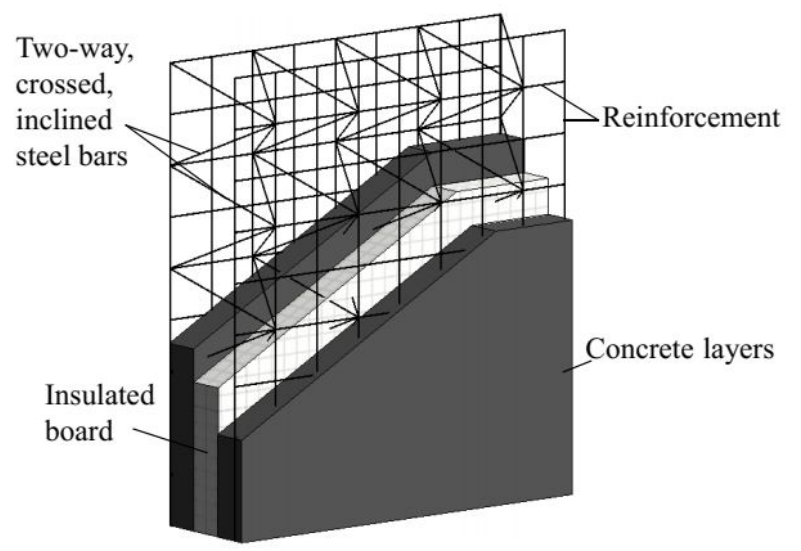

Figure 1.Schematic of load-bearing prefabricated composite wall panel

Wang(2016)examined the statistical data of China Real Estate Evaluation Centre concerning the difference of reinforced-concrete structure constructions between industrial method and the traditional cast-in-place concrete construction method. It was found that the former method reduces the energy consumption by $20 \% \sim 30 \%$, material loss by $60 \%$, construction rubbish by $83 \%$, and recyclable materials by $66 \%$ compared to the latter method, a combination of which eventually leads to the reduction of carbon emission. Thus, it is advised to construct LPCP building by the industrial method based on in-factory prefabrication and field assembly of the construction parts, which not only delivers the advantage of reinforcedconcrete structure, but can also reduce the energy consumption and carbon emission, making this new structure particularly promising. 
Research indicates that this type of sandwich plate exhibits good load bearing capacity and ductility with the presence of axial vertical load (Rodrigo et al, 2013; Mohamad et al, 2013; Benayoune et al, 2007), eccentric vertical load (Mohamad et al, 2011; Benayoune et al, 2006), bending (Isabella et al, 2015; Smitha et al, 2014; Ramachandra et al, 2014; Benayoune et al, 2008), shear force (Liu et al, 2013; Waiel et al, 2009; Wu et al, 2006), compressive-bendingshear composite load (Kabir, 2005), and seismic load (Janardhana et al,2014; Magliulo et al, 2014; Retamales et al, 2013), making it suitable to be used as the main load-bearing component in multi-story building structures. This conclusion provided an idea that the LPCP, a kind of seismic resistance and energy saving prefabricated sandwich wall panel, also could be applied in the multi-storey buildings to improve the seismic resistance in rural area of China. Thus, Huang et al(Huang et al, 2014, 2018) investigated the seismic performance of the LPCP by testing and numerical simulation. The results indicated that the seismic performance indexes such as bearing capacity, deformation capacity and energy dissipation capacity can meet the corresponding seismic fortification requirements. However, LPCP is a kind of prefabricated component, which needs to be transported to the site for assembly to form a structure. Connections method between components, components and foundations, and whether the aseismic performance indicators of the assembled structure can meet the requirements of aseismic fortification still needs further research.

To address this gap in the knowledge, this paper details the design, construction, and testing of a 1:2 scale model of an LPCP building structure. Quasi-static testing was undertaken to obtain damage characteristics, yield load, and load-displacement curves of the building structure in response to the simulated seismic conditions. This work allows us to determine whether a suite of seismic performance indicators, e.g., load-bearing capacity, ductility, and 
energy-dissipating ability, can meet the seismic performance requirements of rural building structure.

\section{LPCP Prototype Testing}

\subsection{Reference building}

The specimen is prototyped based on a rural building in the City of Leshan in China's Sichuan Province. This reference building is $13.2 \mathrm{~m}$ tall and has a storey height of $3.3 \mathrm{~m}$. The standard floor layout and the cross-section plot of the building are shown in Fig. 2. The Seismic Precautionary Intensity is set to 7 according to the code for design of buildings of China (2010). Here the Seismic Precautionary Intensity refers to the seismic intensity prescribed by the national regulation for benchmarking the seismic performance of buildings in the local area. It is calculated as the seismic intensity the local area has more than $10 \%$ likelihood to experience within five decades. The seismic intensity refers to the extent to which the ground and buildings are damaged during an earthquake. The level 7 of Seismic Precautionary Intensity corresponds to a design basic acceleration of ground motion of $0.1 \mathrm{~g}$ ( $\mathrm{g}$ is the gravitational acceleration). The site type is category II, corresponding to the $3^{\text {rd }}$ group of seismic ground motion. It is classified based on an array of factors, including the thickness of the construction site cover layer and the equivalent shear wave velocity within the soil layer. It is used to reflect the cumulative amplification effect of the ground condition on the bedrock's seismic vibration. In this case, the test site ground primarily consists of gravel soil, with a cover layer thickness of $20.7 \mathrm{~m}$ and a soil layer equivalent shear wave velocity of $245 \mathrm{~m} / \mathrm{s}$, which make it a category II site according to the regulation of building seismic performance. The floor, roof and wall panels are all based on the newly proposed LPCP. A representative portion of the reference structure was the room located at the intersection of line $2 \sim 3$ and line $A \sim B$ at the ground floor of the building, as shown in the shaded part of Fig. 2. The length and height of the wall and the floor in this room are all 
$1213300 \mathrm{~mm}$. The wall thickness is $200 \mathrm{~mm}$, which contains a $100 \mathrm{~mm}$ thick thermal insulation

122 sandwich layer and two $50 \mathrm{~mm}$ thick concrete surface layers. The floor is $160 \mathrm{~mm}$ thick, with

123 the thermal insulation sandwich layer in the middle being $60 \mathrm{~mm}$ thick, and the concrete layers

124 on both sides being $50 \mathrm{~mm}$ thick. The walls are connected with cast-in-place concrete structural

125 columns, and the walls are connected to the floor using cast-in-place concrete ring beams. The

126 rationale behind this design lies in the fact that the cast-in-place concrete is cheap to make, easy

127 to implement, making it suitable for rural areas with limited economic and construction 128 technology levels.

(a)

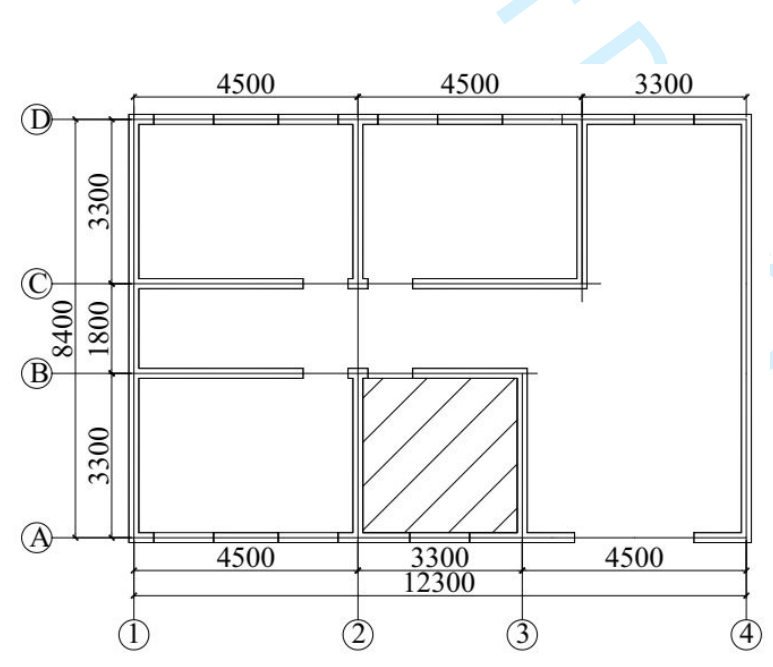

(b)

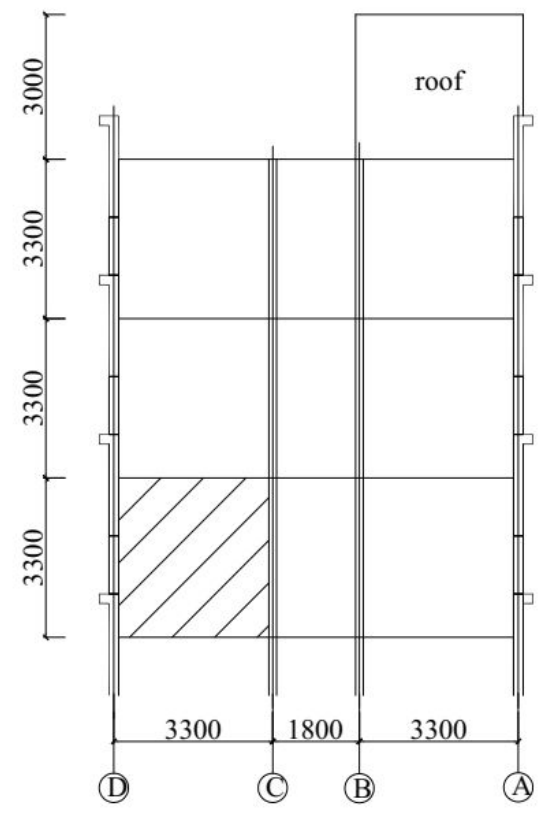

129 Figure 2. Standard floor layout and cross-section view of building prototype: (a) standard floor

130 layout and (b) crossed-section drawn

$131 \quad$ 2.2Scaled test specimen

132 The test specimen is a 1:2 scale model of the representative portion of the prototype building.

133 The specimen size, material parameters, and loads were calculated using similarity theory

134 (Huang, 2013) and dimensionless analysis are shown in Table 1.

135 
136 Table 1. Ratio of similitude

\begin{tabular}{cccc}
\hline Type & Parameters & Similar relation & Scale \\
\hline \multirow{4}{*}{ Specimen } & Length, $L$ & $S_{L}$ & $1 / 2$ \\
size & Area, $A$ & $S_{A}=S_{L}{ }^{2}$ & $1 / 4$ \\
& Displacement, $x$ & $S_{x}=S_{L}$ & $1 / 2$ \\
& Inertia moment, $I$ & $S_{x}=S_{L}{ }^{4}$ & $1 / 16$ \\
\hline \multirow{4}{*}{ Material } & Elasticity modulus, $E$ & $S_{E}$ & \\
parameters & Poisson ratio, $\mu$ & 1 & 1 \\
& Strain, $\varepsilon$ & 1 & \\
& Stress, $\sigma$ & $S_{\sigma}=S_{E} S_{\varepsilon}$ & \\
\hline \multirow{4}{*}{ Loads } & Volume weight, $\rho$ & $S_{\rho}=S_{\sigma} / S_{L}$ & $1 / 4$ \\
& Earthquake force, $F$ & $S_{F}=S_{E} S_{L}{ }^{2}$ & $1 / 4$ \\
& Shear force, $V$ & $S_{V}=S_{E} S_{L}{ }^{2}$ & $1 / 4$ \\
& Axial force, $N$ & $S_{N}=S_{E} S_{L}{ }^{2}$ & $1 / 8$ \\
\hline
\end{tabular}

The floor layout and the cross-sectional view of the specimen are shown in Fig. 3. The floor

138 has a plan area of $1670 \mathrm{~mm} \times 1670 \mathrm{~mm}$, being $20 \mathrm{~mm}$ larger than the room $(1650 \mathrm{~mm} \times 1650$

$139 \mathrm{~mm}$ ) to facilitate its connection to the wall. For the sake of simplification, the door and window

140 openings are both located at the centre of the wall.

141 The dimensions of wall and floor and the associated reinforcement strategy are shown in

142 Fig. 4. The width and height of the wall are both $1650 \mathrm{~mm}$. The wall thickness is $100 \mathrm{~mm}$, with

143 the thermal insulation layer and two concrete layers on both sides being $50 \mathrm{~mm}$ and $25 \mathrm{~mm}$

144 thick, respectively. The length and width of the floor are both $1670 \mathrm{~mm}$. The floor thickness is

$14580 \mathrm{~mm}$, with the thermal insulation layer and concrete surface layers on both sides being 30

$146 \mathrm{~mm}$ and $25 \mathrm{~mm}$ thick, respectively. A galvanized steel wire mesh with $2 \mathrm{~mm}$ diameter steel

147 wire diameter and $200 \mathrm{~mm}$ spacing are placed at the centre of concrete layer, which is connected

148 with a set of two-way slanted galvanized steel wires also being $2 \mathrm{~mm}$ in diameter and at 200

149 mm centres. 
(a)

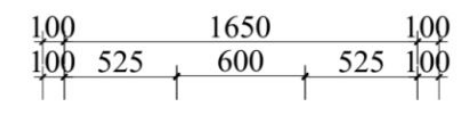

9

(c)
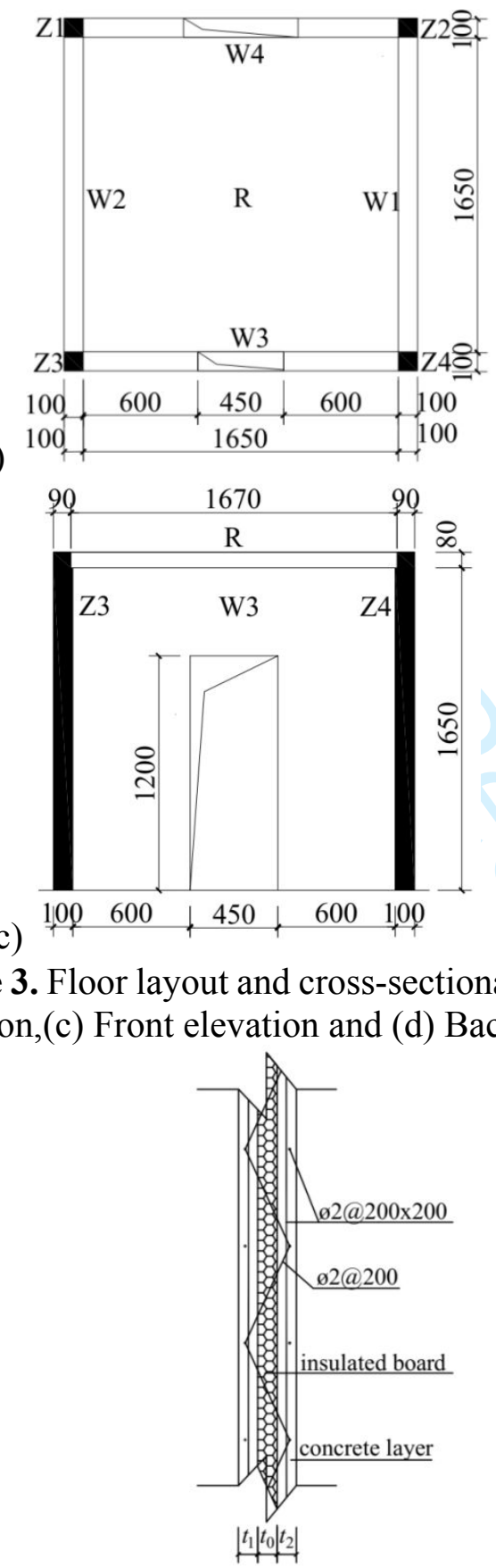

Figure 4. The specimen cross-sectional details (b)

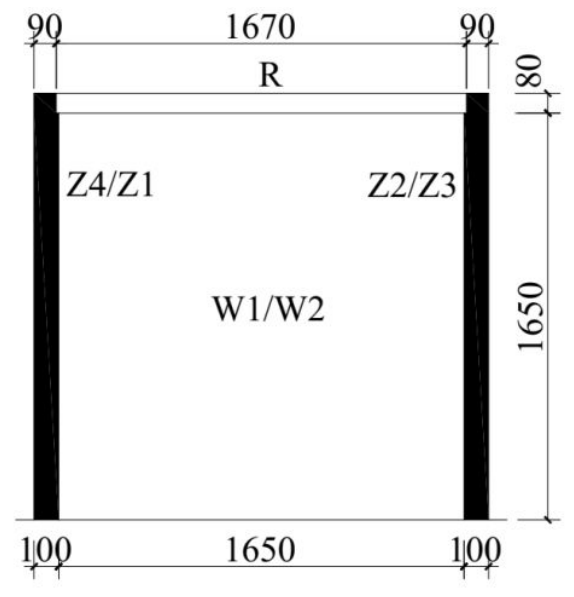

(d)

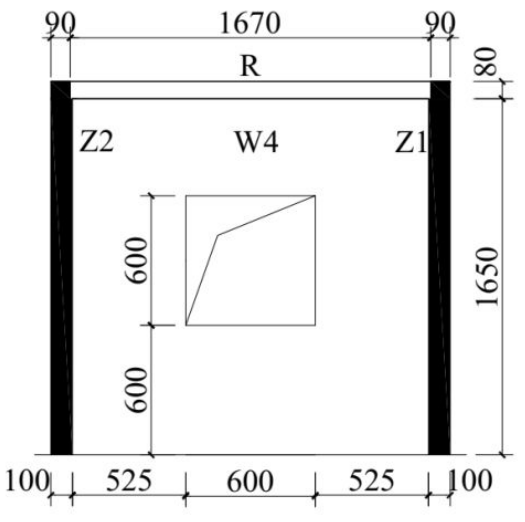

Figure 3. Floor layout and cross-sectional view of the test specimen:(a) Plane figure,(b) Side elevation,(c) Front elevation and (d) Back elevation

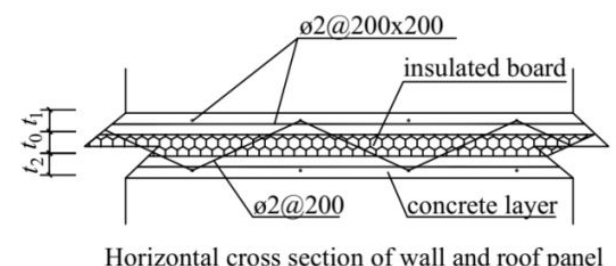

Note: $t_{1}=t_{2}=25 \mathrm{~mm}$;

$t_{0}$ of the wall panel is $50 \mathrm{~mm}$;

$t_{0}$ of the roof panel is $30 \mathrm{~mm}$.

153 connection is established based on cast-in-place concrete structural columns being $100 \mathrm{~mm}$ by

$154100 \mathrm{~mm}$. The longitudinal bars are based on four plain round reinforcing bars of $8 \mathrm{~mm}$ in 
155 diameter. Stirrups are plain round reinforcing bars are $4 \mathrm{~mm}$ in diameter with $75 \mathrm{~mm}$ spacing.

156 The connection between wall and floor is through cast-in-place concrete ring beams, with a

157 cross-section of $90 \mathrm{~mm}$ by $80 \mathrm{~mm}$. The longitudinal reinforcement consists of four plain round

158 reinforcing bars $6 \mathrm{~mm}$ in diameter, transverse reinforcement consists of plain round reinforcing

159 bars $4 \mathrm{~mm}$ in diameter with $100 \mathrm{~mm}$ spacing. The anchor connection between wall and

160 foundation is established by extending the longitudinal galvanized steel wire in the wall to a

161 height above the foundation by $1 / 3$ of the overall height.

(a)

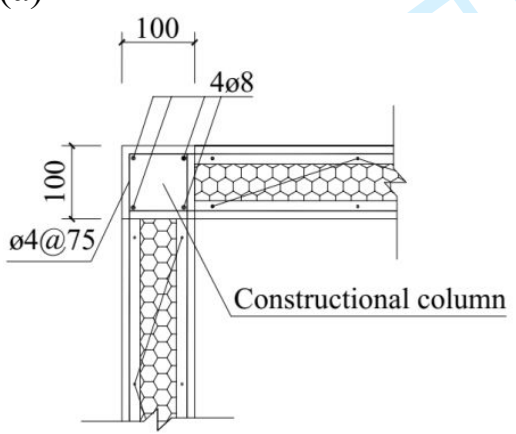

(b)

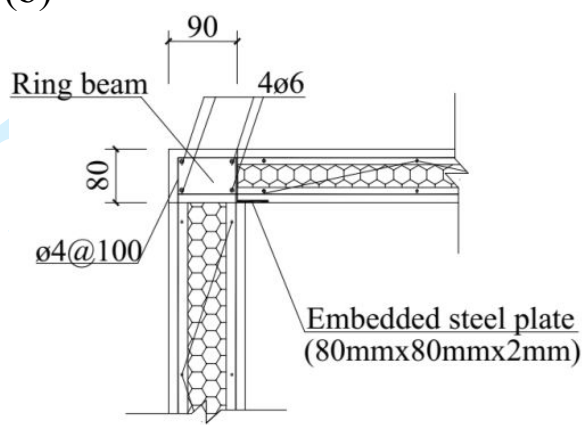

(c)

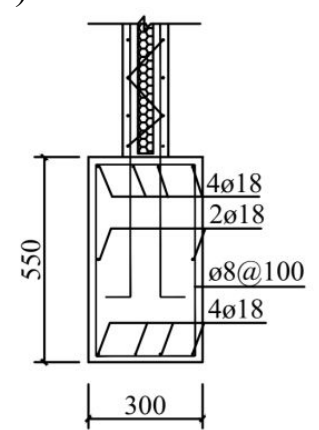

Figure 5. Connection between wall and other walls, floor, and foundation beam: (a) Connection between walls, (b) Connection between wall and roof panel and (c) Connection between wall and foundation beam

\subsection{Materials}

163

The test specimen mainly consists of concrete and reinforcing bars. The foundation is made

164 of regular concrete with a design strength of $35 \mathrm{MPa}$, and all the other components are made of

165 fine stone concrete with a design strength of 30MPa.The corresponding compositions are 166 shown in Table 2 and Table 3, respectively. The main purpose of the present testing is to assess

167 the overall seismic performance of the upper building structure as well as the reliability of the

168 connections between components. To prevent the foundation from undergoing damage before

169 the upper structure, the design strength of the foundation concrete is higher than those of the

170 other components. Besides, considering that all the other components except for the foundation 
171 are relatively small, fine stone concrete is used to build those components so as to facilitate the

172 pouring and vibration operations.

173 The measured concrete strengths are shown in Table 4. The strength measurements were

174 carried out at a factory of prefabricated parts in the city of Leshan. The concrete of all the

175 prefabricated parts are commercially-available self-made concrete produced by the factory,

176 whose actual strength typically exceeds the design value. Table 5 shows the measured strengths

177 of the reinforcing bars.

178 Table 2. Composition of fine aggregate concrete of $35 \mathrm{MPa}$ mix as proportion of cement content

\begin{tabular}{cccc}
\hline Cement(42.5N) & River sand $(0.35 \sim 0.5 \mathrm{~mm})$ & Gravel $(5 \sim 31.5 \mathrm{~mm})$ & Water \\
\hline 1 & 1.11 & 2.72 & 0.38 \\
\hline
\end{tabular}

Table 3.Composition of regular aggregate concrete of $30 \mathrm{MPa}$ mix as proportion of cement 181 content

\begin{tabular}{cccc}
\hline Cement(42.5N) & River sand $(0.35 \sim 0.5 \mathrm{~mm})$ & Fine gravel $(5 \sim 8 \mathrm{~mm})$ & Water \\
\hline 1 & 1.46 & 3.22 & 0.52 \\
\hline
\end{tabular}

182

183 Table 4. The measured average compressive strength of concrete

\begin{tabular}{ccc}
\hline Concrete type & $\begin{array}{c}\text { Average compressive } \\
\text { strength (MPa) }\end{array}$ & Application \\
\hline Regular aggregate & 53.7 & Foundation beam (First concreting) \\
concrete of C35 & 51.0 & Foundation beam (Second concreting) \\
\hline Fine aggregate & 42.4 & Walls, roof panel \\
concrete of C30 & 43.4 & Structural column, ring beam \\
\hline
\end{tabular}

185 Table 5. Mechanical properties of steel bar and zinc-coated wire

\begin{tabular}{|c|c|c|c|}
\hline Type & $\begin{array}{l}\text { Reinforcement } \\
\text { diameter }\end{array}$ & Yield strength $\quad(\mathrm{MPa})$ & $\begin{array}{l}\text { Tensile Strength } \\
\text { (MPa) }\end{array}$ \\
\hline Galvanized steel wire & $2 \mathrm{~mm}$ & 392 & 490 \\
\hline \multirow{3}{*}{ Hot rolled plain steel bars } & $4 \mathrm{~mm}$ & 401 & 745 \\
\hline & $6 \mathrm{~mm}$ & 506 & 724 \\
\hline & $8 \mathrm{~mm}$ & 545 & 609 \\
\hline
\end{tabular}

\subsection{Specimen fabrication}

187 The specimen was prepared through factory prefabrication and field assembly so as to mimic

188 the industrial workflow for constructing buildings with LPCP. The key steps included: setup of 
189 foundation form, binding of foundation reinforcing bars, reservation of structural column

190 reinforcing bars, pouring and curing of foundation concrete (first time), prefabrication of LPCP,

191 installation of LPCP, binding of structural column and ring beam reinforcing bars, pouring and

192 curing of structural column and ring beam concrete, pouring and curing of foundation concrete

193 (second time), and establishment of specimen. The foundation was cast in a two-step process.

194 Initially one third of the foundation height was cast, to fix the reinforcing bars. After the LPCP

195 was in place, the remaining foundation concrete was poured together with the structural column

196 and the ring beam, so as to establish the connection between foundation and the component

197 above it.

198 3. Testing

$199 \quad$ 3.1 Test set up

200 Both vertical and horizontal loads are applied in the present testing. During the experiment, 201 vertical load is first applied, followed by the application of horizontal load while maintaining a 202 constant vertical load. The vertical load is applied to mimic the load from the top of the room 203 and the live load from the floor. Through calculation, it is determined that the load from the top 204 of the room is $50 \mathrm{kN}$, while the live load from the floor is $0.5 \mathrm{kN} / \mathrm{m}^{2}$.

205 The horizontal load is applied through multiple cycles to model the pattern of reciprocating 206 force and deformation change during an earthquake. The seismic precautionary intensity is set 207 to 7 , and the design basic acceleration of ground motion is set to $0.1 g$. Calculation indicates 208 that, with a horizontal earthquake, the ultimate capacity of specimen is predicted to be $220 \mathrm{kN}$. 209 The horizontal load is applied in stepwise cyclic manner toward positive direction. The 210 incremental change of each cycle is set to $1 / 10$ of the predicted ultimate capacity, i.e., starting 211 off from $20 \mathrm{kN}$ and adding load in a cyclic stepwise manner until the specimen failure.

212 3.2Loading apparatus 
213 The specimen is mounted to the ground base slot through four $65 \mathrm{~mm}$ diameter 900MP a yield 214 strength anchor bolts. Meanwhile, horizontal supports are set at both sides of the foundation to 215 prevent the foundation from undergoing lateral movement during loading process (Fig. 6).The 216 field picture of loading devices is shown in Fig. 7.

217 The load transferred from the top of the room was simulated with a vertical servo actuator 218 (maximum force is $2 \mathrm{MN}$ ). First, $50 \mathrm{kN}$ of concentrated load was applied to a $200 \mathrm{~mm}$ by 200 $219 \mathrm{~mm}$ by $10 \mathrm{~mm}$ steel plate through the vertical servo actuator; the load was in turn propagated 220 to a large steel plate being $1890 \mathrm{~mm} \times 1890 \mathrm{~mm} \times 20 \mathrm{~mm}$, which converted the concentrated load 221 to a linear load being applied to an I-type steel beam. The I-type beam propagates the load to a 222 ring beam. Four rolling bars $32 \mathrm{~mm}$ in diameter were placed between the small steel plate and 223 the large steel plate to ensure that the specimen could move freely within $\pm 100 \mathrm{~mm}$ during the 224 horizontal loading process. A live load of $0.5 \mathrm{kN} / \mathrm{m}^{2}$ was applied through gravel uniformly 225 distributed on the floor of the specimen.

226 The load step was $20 \mathrm{kN}$ according to simple calculation. When the specimens cracked, the 227 testing load was controlled by displacement and each load step with an increment of 3.0 times 228 of the crack displacement $\Delta \mathrm{cr}$. When the wall was completely failed or the loading decreased 229 to 0.85 times the ultimate load, the test stopped. The horizontal load was applied through a 230 horizontal servo actuator (maximum force is $2 \mathrm{MN}$ ) mounted to the counter wall. A $600 \mathrm{~mm} \times$ $231300 \mathrm{~mm} \times 20 \mathrm{~mm}$ rectangular steel plate was placed at the front of the horizontal servo actuator, 232 which was connected to a $1890 \mathrm{~mm} \times 1890 \mathrm{~mm} \times 20 \mathrm{~mm}$ thick rectangular steel plate at the front 233 of the specimen through four bolts $36 \mathrm{~mm}$ in diameter and $500 \mathrm{MPa}$ in yield strength. This 234 configuration allowed the horizontal load to be evenly propagated to the ring beam at the front 235 of the specimen. A ball joint was place in a built-in force sensor in the horizontal servo actuator, 
which allowed the horizontal servo actuator to rotate in response to the movement of the 237 specimen so as to ensure the stability of horizontal loading process.

(a)

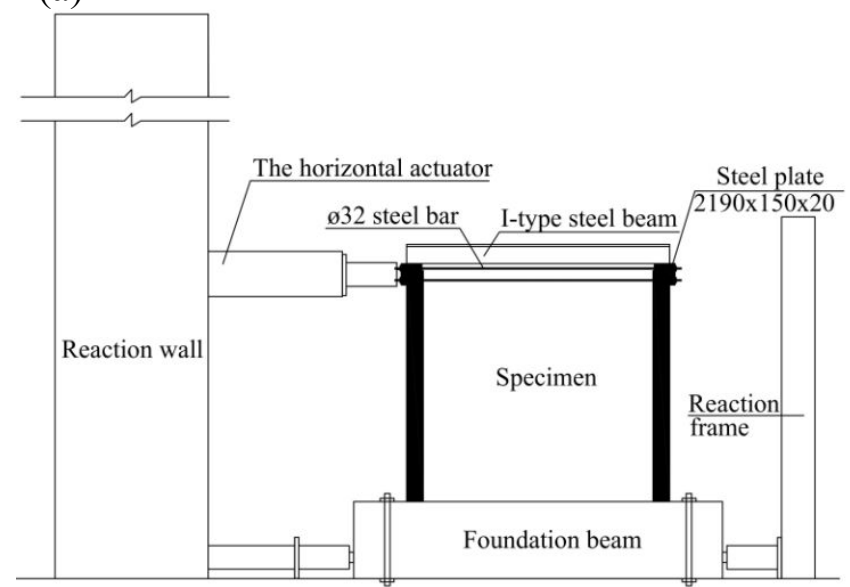

(b)

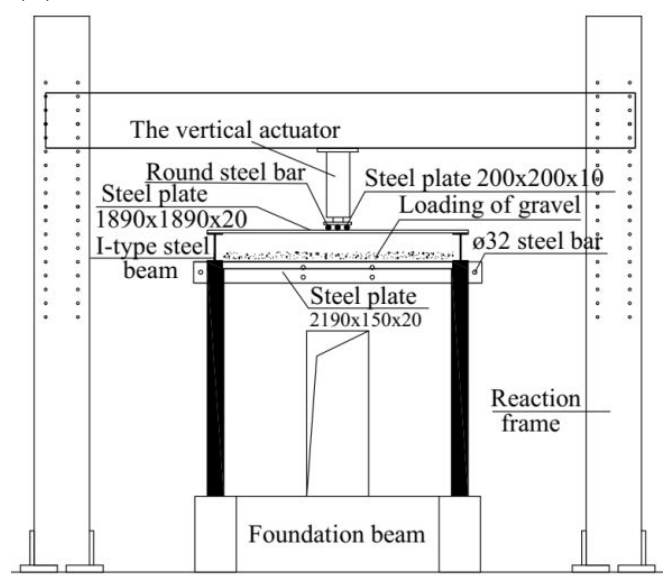

Figure 6. Schematic diagrams of horizontal and vertical loading devices: (a) device for horizontal loading and (b) device for vertical loading

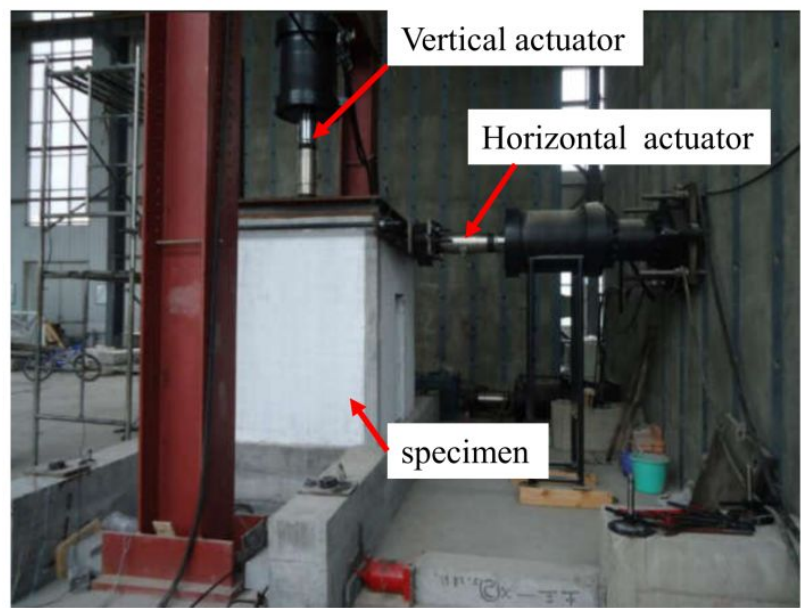

$240 \quad$ Figure 7.Field picture of loading device

\subsection{Experimental measurement}

The parameters measured during the present testing were: 1)horizontal displacement

2)corresponding lateral load at the top of the specimen and 3)the growth and distribution of

244 cracks in the specimen.

245 The horizontal displacement at the top of the specimen is measured with a laser 246 displacement sensor located at the centre of the specimen ring beam. Meanwhile, a dial 247 indicator was used to measure the sliding displacement of the foundation at the centre of the 
248 specimen foundation during the loading process so as to eliminate the impact of foundation 249 slippage on the measurement of specimen displacement. The horizontal load was controlled 250 and measured through the control unit of the horizontal servo actuator.

251 To facilitate the observation of crack growth, a layer of white lime paint was uniformly 252 applied to the surface of the specimen wall, and a $100 \mathrm{~mm} \times 100 \mathrm{~mm}$ grid was drawn on the 253 paint using a pencil. During the loading process, a real time observation of the crack initiation, 254 growth, and distribution was conducted, with the shape and direction of the cracks marked out. 255 Evolution of the horizontal load was recorded, and a tape measure and a crack observer are 256 employed to recording the length and width of the crack.

\section{4. Results}

\section{$258 \quad$ 4.1Ultimate capacity}

259 The cracking, ultimate, and failure loads of the sample and the corresponding horizontal 260 displacements are shown in Table 6. The cracking load was recorded when the first visible 261 crack appears on the surface of the sample; the ultimate load corresponds to the peak load the 262 sample was able to withstand during the loading process; the failure loads was recorded when 263 the load-bearing capacity of the sample drops to $85 \%$ of the ultimate load.

264 Table 6.Measured horizontal loads and displacements of specimen

\begin{tabular}{cccccc}
\hline \multicolumn{2}{c}{ Cracking stage } & \multicolumn{2}{c}{ Ultimate stage } & \multicolumn{2}{c}{ Failure stage } \\
$P_{\mathrm{cr}}(\mathrm{kN})$ & $\Delta_{\mathrm{cr}}(\mathrm{mm})$ & $P_{\max }(\mathrm{kN})$ & $\Delta_{\max }(\mathrm{mm})$ & $P_{\mathrm{u}}(\mathrm{kN})$ & $\Delta_{\mathrm{u}}(\mathrm{mm})$ \\
\hline 160 & 4.39 & 370 & 19.97 & 300 & 43.48 \\
\hline
\end{tabular}

\section{$265 \quad 4.2$ Damage process}

266 Table 7 shows the damage process of the specimen under the vertical load $F_{\mathrm{v}}=50 \mathrm{kN}$ and floor 267 live load $q_{\mathrm{v}}=0.5 \mathrm{kN} / \mathrm{m}^{2}$, while the initiation, growth, and distribution of the cracks were shown 268 in Fig. 8. 
270 Table 7.Process of specimen damage

\begin{tabular}{|c|c|c|}
\hline Horizontal load & Damage process & Comments \\
\hline $0-140 \mathrm{kN}$ & - $\quad$ Specimen intact; no visible cracking & \\
\hline $160 \mathrm{kN}$ & $\begin{array}{l}\text { - Fine horizontal cracks appear at the bottom of the structural } \\
\text { column Z4 }\end{array}$ & $\begin{array}{l}\text { Appearance of } \\
\text { the first crack }\end{array}$ \\
\hline $180 \mathrm{kN}$ & $\begin{array}{l}\text { - New fine cracks appear and grow along slanted directions } 50 \mathrm{~mm} \\
\text { above the bottom of the structural column } \mathrm{Z4}\end{array}$ & \\
\hline $200 \mathrm{kN}$ & $\begin{array}{l}\text { The width and length of the existing cracks in the structural } \\
\text { column Z4 further increase. } \\
\text { - Fine horizontal cracks appear at the connection between the wall } \\
\text { W1 and the foundation, with the paint on the wall at the connection } \\
\text { peeling off slightly. }\end{array}$ & \\
\hline $220 \mathrm{kN}$ & $\begin{array}{l}\text { - A } 100 \mathrm{~mm} \text { long and } 0.3 \mathrm{~mm} \text { wide crack as well as a slanted } 80 \\
\text { mm long and } 0.3 \mathrm{~mm} \text { wide crack appear } 200 \mathrm{~mm} \text { above the } \\
\text { bottom of the structural column } \mathrm{Z} 4 \text {. }\end{array}$ & \\
\hline $240 \mathrm{kN}$ & $\begin{array}{l}\text { The horizontal crack } 200 \mathrm{~mm} \text { above the bottom of the structural } \\
\text { column Z4 starts to propagate into the wall W3. }\end{array}$ & \\
\hline $260 \mathrm{kN}$ & $\begin{array}{l}\text { - The horizontal crack reaching the wall W3 starts to grow along a } \\
\text { slanted direction toward the bottom of the wall. } \\
\text { A new crack appear } 300 \mathrm{~mm} \text { above the bottom of the structural } \\
\text { column Z4 }\end{array}$ & \\
\hline $280 \mathrm{kN}$ & $\begin{array}{l}\text { The horizontal crack reaching the wall W3 finally reaches the } \\
\text { bottom of the wall along a slanted direction. }\end{array}$ & \\
\hline $300 \mathrm{kN}$ & $\begin{array}{l}\text { The length, width, and depth of the existing cracks in the structural } \\
\text { column and wall further increase, while an array of new cracks also } \\
\text { appear. } \\
\text { A horizontal crack } 80 \mathrm{~mm} \text { long and } 0.6 \mathrm{~mm} \text { wide appears } 450 \mathrm{~mm} \\
\text { above the bottom of the structural column } \mathrm{Z} 4 \text {. } \\
\text { - The crack at the bottom of the structural column } \mathrm{Z} 4 \text { extends to the } \\
\text { wall W1. } \\
720 \mathrm{~mm} \text { above the bottom of the wall } \mathrm{W} 2 \text {. } \\
75^{\circ} \text { slanted major } 0.8 \mathrm{~mm} \text { wide appears } \\
\text { A new crack } 600 \mathrm{~mm} \text { long and } 0.8 \mathrm{~mm} \text { wide appear at the door } \\
\text { hole of the wall W3, which first grows along } 45^{\circ} \text { direction, and then } \\
\text { grows vertically. }\end{array}$ & \\
\hline $320 \mathrm{kN}$ & $\begin{array}{l}\text { - A horizontal crack } 100 \mathrm{~mm} \text { long and } 0.5 \mathrm{~mm} \text { wide appears } 500 \mathrm{~mm} \\
\text { above the bottom of the structural column } \mathrm{Z} 4 \text {. } \\
\text { - The } 45^{\circ} \text { slanted major crack in the wall W2 continues to extend } \\
\text { toward the bottom in an inclined manner; meanwhile, new fine cracks } \\
\text { appear at the bottom. } \\
\text { - The slanted crack at the door hole of the wall W3 further grows. }\end{array}$ & \\
\hline $340 \mathrm{kN}$ & $\begin{array}{l}\text { - A new slanted crack appears at a location above the bottom of the } \\
\text { structural column Z3 by a clearance of } 2 / 3 \text { of the overall column height; } \\
\text { the crack grows into the wall } \mathrm{W} 2 \text {, with the length and width being } 150 \\
\mathrm{~mm} \text { and } 0.4 \mathrm{~mm} \text {, respectively. } \\
\text { - A new horizontal crack } 200 \mathrm{~mm} \text { long and } 0.6 \mathrm{~mm} \text { wide appears on } \\
\text { the right hand side } 330 \mathrm{~mm} \text { above the bottom of the wall W3. } \\
\text { The } 45^{0} \text { slanted major crack in the wall } \mathrm{W} 2 \text { reaches the bottom of } \\
\text { the wall. }\end{array}$ & \\
\hline $360 \mathrm{kN}$ & $\begin{array}{l}\text { A new slanted crack } 100 \mathrm{~mm} \text { long and } 0.5 \mathrm{~mm} \text { wide appears at a } \\
\text { location above the bottom of the structural column } \mathrm{Z} 4 \text { by a clearance of } \\
4 / 5 \text { of the column height. }\end{array}$ & \\
\hline $370 \mathrm{kN}$ & $\begin{array}{l}\text { The specimen reaches its ultimate capacity, showing significant } \\
\text { plastic deformation. }\end{array}$ & $\begin{array}{l}\text { All cracks } \\
\text { appear }\end{array}$ \\
\hline
\end{tabular}


- A new horizontal crack $100 \mathrm{~mm}$ long and $0.4 \mathrm{~mm}$ wide appears $100 \mathrm{~mm}$ above the bottom of the structural column $\mathrm{Z} 3$.

- A horizontal crack $460 \mathrm{~mm}$ long and $0.8 \mathrm{~mm}$ wide appears $230 \mathrm{~mm}$ above the bottom, which then grows into the wall W2.

- A multitude of new slanted cracks appear at the door hole of the wall W3.

- A slanted crack $200 \mathrm{~mm}$ long and $0.4 \mathrm{~mm}$ wide appears $500 \mathrm{~mm}$ above the bottom; the bottom concrete experiences cracking and detachment.

- $\quad$ The load-bearing capacity of specimen starts to decline; a full damage of specimen occurs when the load-bearing capacity reaches $85 \%$ of the ultimate capacity (approximately $300 \mathrm{kN}$ ).

- When the full damage occurs, the concrete at the bottom of the

$300 \mathrm{kN} \quad$ stretched structural columns (Z4、 Z3) experiences severe cracking and detachment; the rebars inside the columns are pulled apart from the foundation; subsequently, the concrete at the bottom of the stretched walls (W3, W2, W1) is cracked, the wall is detached from the foundation, and the vertical rebars are partly snapped.
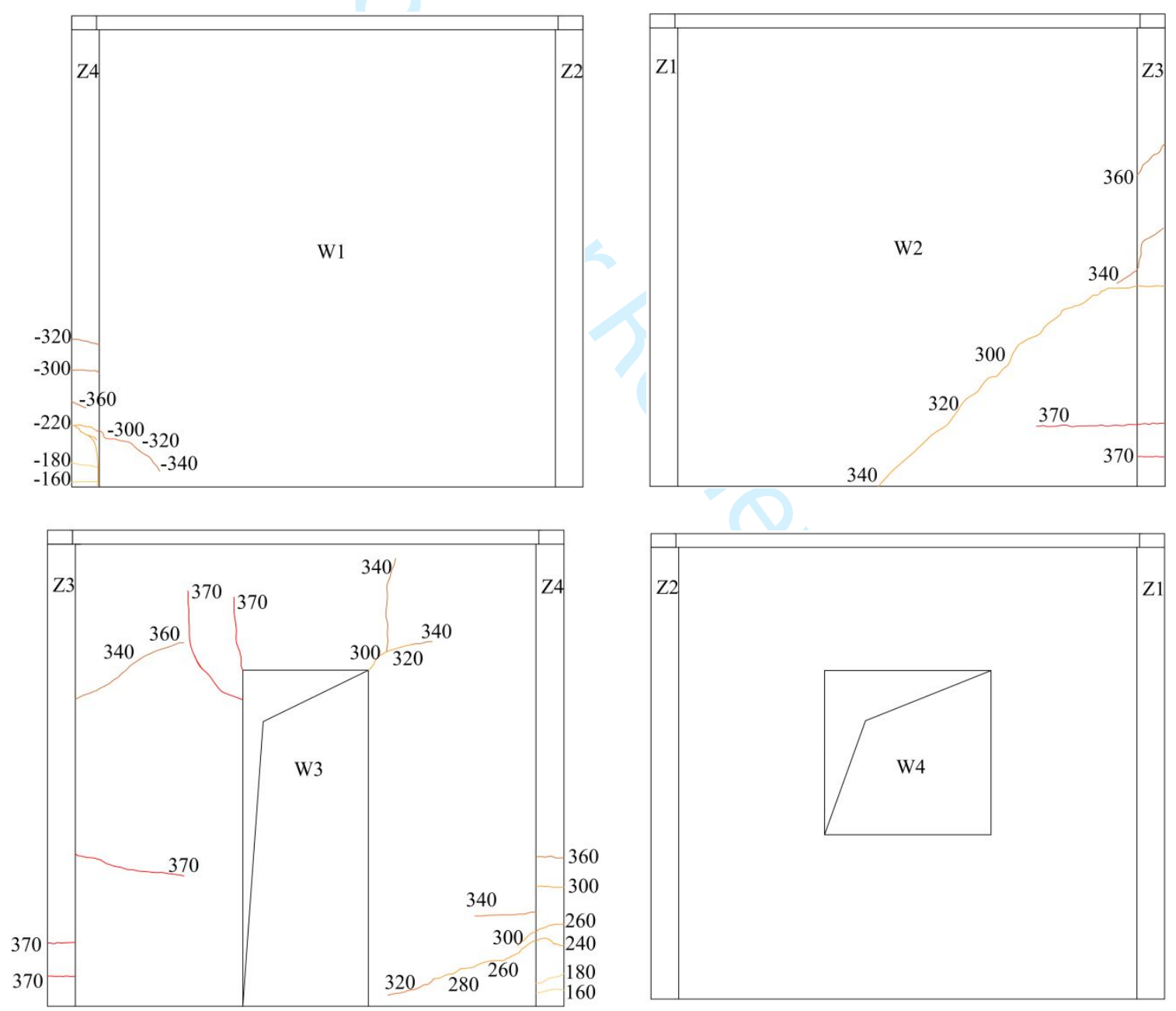

Figure 8. Growth and distribution of cracks of the 4 walls in the specimen 

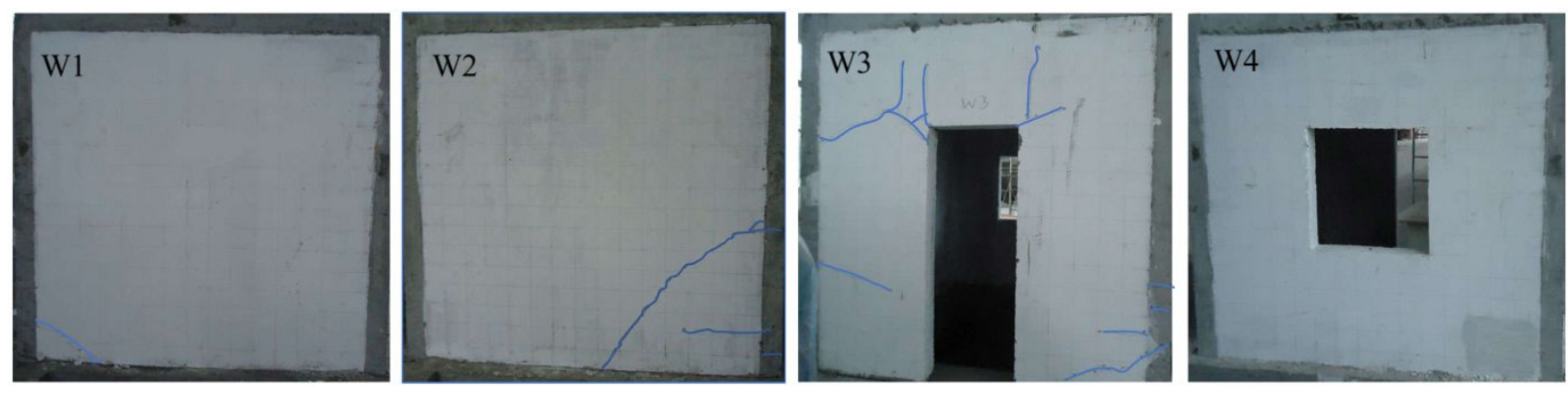

Figure 9. Fully damaged patterns of the 4 walls in the specimen

\section{5. Discussion}

\section{$275 \quad 5.1$ Ultimate capacity}

276 The ultimate capacity of specimen is measured to be $370 \mathrm{kN}$, which is $68 \%$ higher than the 277 predicted ultimate capacity $(220 \mathrm{kN})$. It satisfies the required load-bearing capacity, with a large 278 safety margin, indicating that the predicted ultimate capacity is conservative. It is recommended 279 that further study could be maintaining the safety and reducing cost of the wall by decreasing 280 the strength of the concrete to some extent. For instance, the strength of the roof and wall should 281 be reduced from the current $43.4 \mathrm{MPa}$ to $25 \sim 30 \mathrm{MPa}$, while the foundation's strength could 282 be reduced from the current $53.7 \mathrm{MPa}$ (the 1st pouring) and $51 \mathrm{MPa}$ (the 2nd pouring) to 30 283 MPa which may lead to cost reduction. The ratio of cracking load to ultimate load is 0.43 , while 284 the corresponding ratio of displacements is 0.22 , which indicates that the specimen undergoes 285 substantial deformation as it evolves from the cracking stage to the ultimate capacity stage, and 286 a brittle damage is avoided. The specimen's ratio of damage load to ultimate load is 0.81 , while 287 the corresponding ratio of displacements is 2.2 , which indicates that the specimen still retains 288 its load-bearing capacity and ductility to some extent after the ultimate load is reached.

\section{$289 \quad 5.2$ Damage characteristics}

290 The damage and crack growth processes of the sample are summarized below:

291 - During damage of the specimen, the overall integrity of the building structure can be 292 maintained, indicating that the building structure assembled based on cast-in-place 
293 concrete structural columns and ring beams exhibits a decent level of structural robustness.

294 - The final damage of specimen is found to be as follows: the concrete at the bottom of the 295 structural column (Z1, Z2) on the loading side undergoes a marked cracking, with the 296 reinforcing bars on the loading side within the column pulled apart. Subsequently, the walls 297 on the loading side (W1, W2, W3) gradually detach from the foundation, the galvanized 298 steel wires in the walls are pulled apart, with the specimen's load-bearing capacity dropping 299 to $85 \%$ of the ultimate capacity, which signifies the occurrence of full damage. Therefore, 300 one needs to reinforce the connections among foundation, structural columns, and walls 301 during the design.

302 With the presence of both horizontal stepwise cyclic loading toward positive direction and 303 the vertical loading, most cracks are inclined, being located at the middle and bottom 304 sections of the wall as well as the opening on the loading side. This pattern indicates that 305 the middle and bottom sections of the wall and the opening are the main load-bearing 306 locations and the weak part of the whole structure. As such, these locations need to be 307 reinforced during the design. Meanwhile, it is found that the growth of cracks in the wall 308 is uneven and inadequate. To further improve the wall's energy-dissipating ability, one 309 needs to optimize the building structure based on LPCP.

310 - The thermal insulation sandwich layer is not detached from the concrete layers on both 311 sides, indicating that the various components of LPCP can function in a concerted manner, 312 and the wallboard shows a decent overall integrity.

313 - From the initial loading to the final damage, the specimen roughly undergoes five stages, 314 namely elastic stage, cracking stage, yield stage, limit stage, and damage stage, which 315 shows that the specimen undergoes significant change before the final damage, exhibiting 316 a good ductility. 


\section{$317 \quad$ 5.3Hysteresis curve and skeleton curve}

318 Fig. 10(a) shows the load-displacement curve (hysteresis curve) obtained from the simulated 319 earthquake-induced cyclic loading. It can be seen in Fig. 10(a) that during the initial loading, 320 the load-displacement curve is roughly linear, while the residual deformation is insignificant, 321 i.e., the specimen is in elastic regime. As the horizontal load reaches $160 \mathrm{kN}$, cracks start to 322 appear in the specimen, and residual deformation occurs. As a result, the load-displacement 323 curve is transformed from a linear curve to a loop curve, i.e., a hysteresis loop appears. This 324 indicates that the specimen starts to dissipate the earthquake energy. With an increase of load, 325 the number of cracks in the specimen keeps increasing, the residual deformation becomes 326 increasingly pronounced, the area covered by the hysteresis loop gradually ramps up, and the 327 hysteresis loop starts to exhibit a reversed S shape. A combination of these observations 328 indicates that the specimen's dissipation of seismic energy increases gradually, and slippage 329 occurs. As the ultimate load $370 \mathrm{kN}$ is reached, the specimen's load-bearing capacity starts go 330 down, the area of hysteresis loop further increases, and the slippage becomes more pronounced.

331 This trend continues to progress until the load-bearing capacity drops to $85 \%$ of the ultimate 332 capacity, a point marking the occurrence of full damage. It can be observed from the hysteresis 333 curve that the earthquake-induced deformation characteristics and energy dissipation processes 334 associated with the building structure based on LPCP highly resembles that of the shear wall 335 structure with reinforcing bar concrete. Therefore, one can refer to the shear wall structure with 336 reinforcing bar concrete for earthquake resistant design.

337 By drawing an envelope curve passing through the peak of each load hysteresis curve as 338 derived from the cyclic loading process, one can obtain the skeleton curve of the specimen, as 339 shown in Fig. 10 (b). Before cracks in the specimen appear, the skeleton curve is almost linear, 340 corresponding to a large structural stiffness and the elastic state. As the cracks start to appear, 
341 the slope of the curve starts to decline, i.e., the specimen's horizontal displacement gradually

342 increases for a given incremental load. As the ultimate load is reached, the specimen's load-

343 bearing capacity starts to drop all the way to $85 \%$ of the ultimate capacity, marking the

344 occurrence of full damage. The decline curve is relatively shallow, indicating that the specimen,

345 after the ultimate capacity is reached, still retains a portion of its load-bearing capacity and 346 ductility.
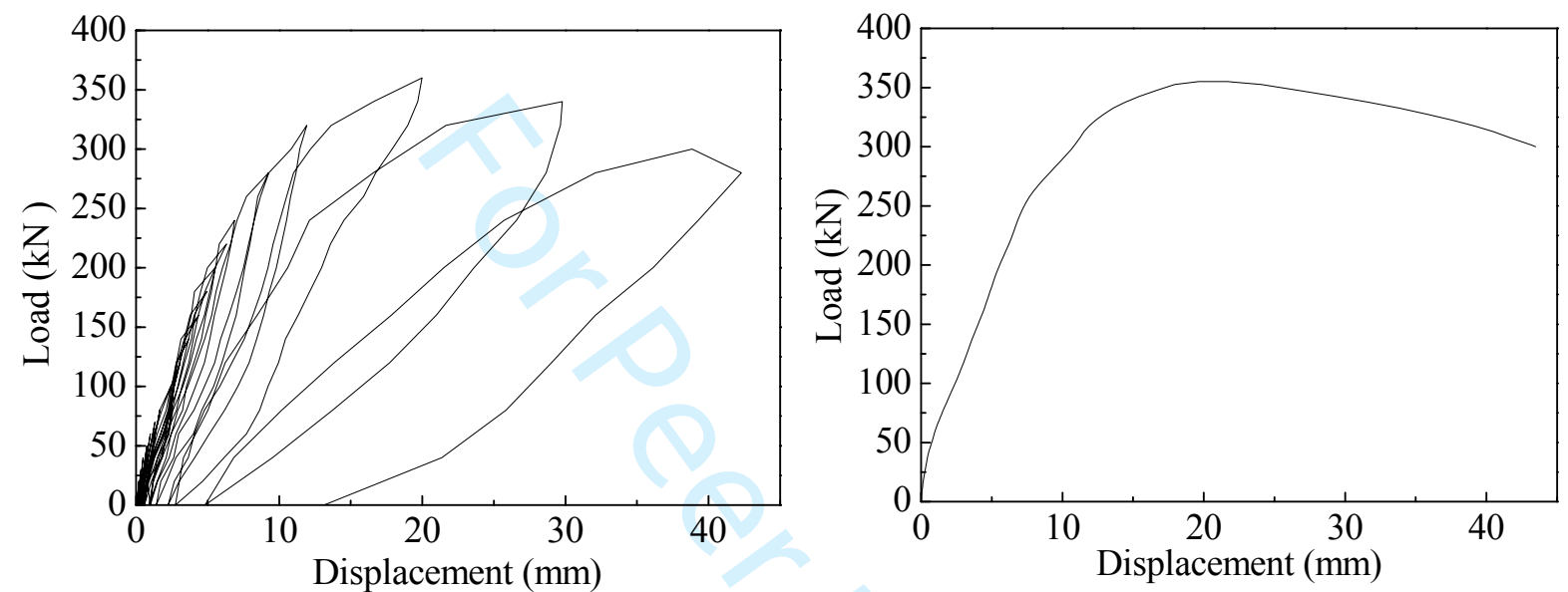

Figure 10.Hysteresis curve and hysteretic skeleton curve of specimen: (a) hysteresis curve and (b)hysteretic skeleton curve

347

348

349

350

\subsection{Stiffness degradation curve}

The specimen's stiffness degradation curve is shown in Fig. 11. The specimen's stiffness degradation process mainly consists of three stages: 1) Rapid decrease of stiffness stage, which corresponds to the process from the point with initial appearance of fine cracks in the concrete to the point with apparent cracks visible to naked eyes; the increase of displacement during this stage is relatively small, while the drop of stiffness is substantial (71\%), i.e., from 142.86 $\mathrm{kN} / \mathrm{mm}$ to $41.42 \mathrm{kN} / \mathrm{mm}$. 2) Moderate decrease of stiffness stage, which corresponds to the point where the specimen undergoes cracking to the point where the ultimate capacity is reached; during this stage the decrease of stiffness becomes much smaller, i.e., from 41.42 $\mathrm{kN} / \mathrm{mm}$ to $18.03 \mathrm{kN} / \mathrm{mm}$, a $12.6 \%$ decrease. (3) Slow decrease of stiffness stage, which corresponds to the point where the ultimate capacity is reached to the point where the full 
358 damage occurs; during this stage, the displacement is substantially raised, whereas the decrease 359 of stiffness is small, i.e., from $18.03 \mathrm{kN} / \mathrm{mm}$ to $6.90 \mathrm{kN} / \mathrm{mm}$, a $7.8 \%$ decrease.

360

361

362

363 364 365 366 367 368 369 370 371 372 373 374 375 376

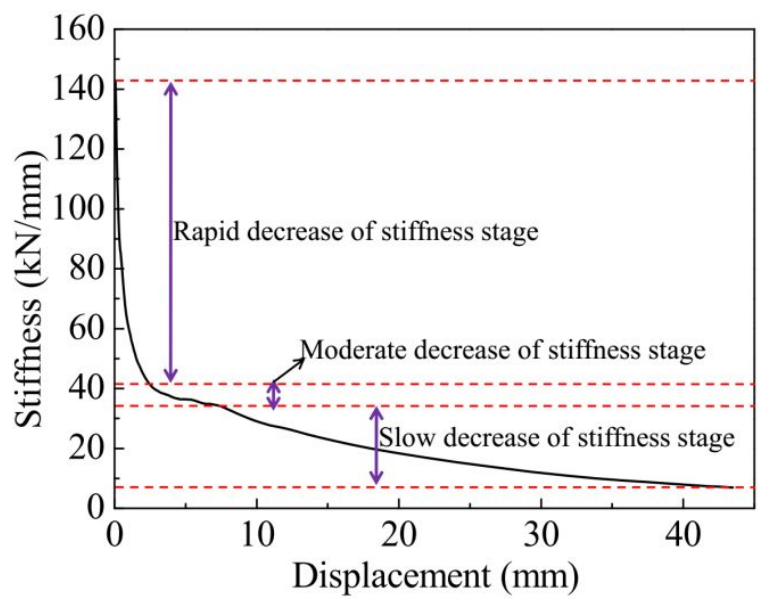

Figure 11.Stiffness degradation curve of specimen

\subsection{Ductility factor}

The ductility factor $\mu$ denotes the ratio of maximum displacement $\Delta_{u}$ to the yield displacement $\Delta_{y}$ when specimen damage occurs, and is used here to assess the structural ductility. Due to the absence of an apparent yield point on the specimen's skeleton curve (Fig. 10(b)), one can use the Generalized Yield Moment Method(GYMM) to determine the yield point.(Liu, 2007; Huang et al, 2018). Fig. 12 outlines the key steps of this method: draw a tangential line $\mathrm{OH}$ going through the origin $O$, and draw a horizontal line that passes through the peak load at $G$; suppose these two lines intersect each other at point $H$; draw a perpendicular line through $H$, which intersects the skeleton curve at $I$; extend the line $O I$ to cross the line $H G$ at point $H^{\prime}$; draw a perpendicular line through $H^{\prime}$, which intersects the skeleton curve at point $B$, which is a decent approximation of the yield point. The yield load and displacement obtained from the aforementioned GYMM was $280 \mathrm{kN}$ and $9.25 \mathrm{~mm}$, respectively. And the maximum displacement was 43.48 mmas showed in Table 6.It is found through calculation that the specimen's ductility factor is 4.7 according to dived the maximum displacement by the yield displacement, which satisfies the seismic regulation dictating that the concrete structural 
377 ductility factor should exceed 3. This indicates that the building structure based on LPCP has 378 decent ductility.

379

380

381

382 383

384

$$
I_{\mathrm{W}}^{\mathrm{S}}=\frac{\sum_{i=1}^{n} P_{i} \Delta_{i}}{P_{y} \Delta_{y}}
$$

385 Where $P_{\mathrm{i}}$ and $\Delta_{i}$ denote the peak load value and the corresponding displacement for the $i$ th 386 cyclic loading; $P_{\mathrm{y}}$ and $\Delta_{\mathrm{y}}$ denote the yield load and displacement values, respectively(Jiang et 387 al, 2007;Huang, 2013). It is found through calculation that the specimen's working index is 388 20.62, which is much larger that these of other composite wallboard structures, e.g., the fibre 389 gypsum board composite wall filled with concrete with a working index of 7 to 8 . One can 390 thereby conclude that the newly proposed building structure based on LPCP can deliver a strong 391 energy-dissipating effect. 


\section{6. Conclusions}

393 This study investigated the overall seismic performance of the LPCP building structure 394 which formed by the connection of cast-in-place concrete ring beam and column based on the 395 results of the previous studies, and obtained the conclusions as follow:

396 1. The structure has a high load-bearing capacity, decent ductility, and strong energy397 dissipating ability, allowing it satisfy the seismic performance requirements concerning 398 China's rural building structure. Meanwhile, the construction workflow based on factory 399 prefabrication and field assembly is conductive to energy conservation, making this $400 \quad$ technology particularly promising.

401 2. The present building structure assembled based on cast-in-place concrete 402 structural columns and ring beams exhibit good structural robustness. Meanwhile, during 403 the loading process, various components in the LPCP can function in a concerted manner, 404 the wall panel has strong integrity.

405 3. The middle and lower sections of the wall and its connection with the foundation 406 are the key load-bearing location and the weak part of the entire structure. Hence, it is 407 recommended to reinforce these places during the design.

\section{Future work}

410 1. The prefabricated concrete wall panels currently suffers from a series of issues, incuding 411 the large size and weight,a stringent requirement on the transportation and installation, and high 412 sensitivity to the rural areas road condition, transportation vehicles, mechanical equipment and 413 construction technology. Future research needs to focus on reducing the weight and size of the 414 LPCP so as to faciliate the transportation in the rural area. 
415 2.The interconncetion of LPCP parts is critical for ensuring the seismic performance of the 416 overall building structure. Hence, future research will study the impact of various 417 interconnection methods on the seismic performance of the LPCP building structures so as to 418 meet the relevant regulations in the rural area.

4193 . The stepwise cyclic loading toward positive direction used in the present experiments 420 cannot authentically mimic the actual earthquake condition. It is thereby advised to conduct 421 improved seismic performance experiments if possible that can more authentically reflect the 422 impact of earthquake, e.g., shaking table test. 423

\section{Acknowledgements}

425 The author would like to thank for the financial sponsorship of Southwest Jiaotong University, 426 which provided the first fund to open this research subject (Grant No. 10101X10096060). This 427 project has also been supported financially also by Project of Young Scientists Fund (Grant No. 428 51808454, 51508472), Science and Technology Innovation Project of the Fundamental 429 Research Funds for the Central Universities (Grant No.10101B10096033) and Science and 430 Technology Citizen-Benefiting Project of Chengdu City (Grant No. 2015-HM01-00063-SF).

\section{$431 \quad$ Statement}

432 The Author(s) declare(s) that there is no conflict of interest.

\section{References}

434 Bai J , Cheng F, Jin S, Ou J(2019) Assessing and Quantifying the earthquake response of 435 reinforced concrete buckling-restrained brace frame structures. Bulletin of Earthquake $436 \quad$ Engineering, 17:3847-3871. 
437 Benayoune A, Abdul A and Samad A (2008) Flexural behaviour of pre-cast concrete sandwich 438 wallboard-Experimental and theoretical investigations. Construction and Building Materials, $439 \quad 22(1): 580-592$.

440 Benayoune A, Samad A AA, Ali A AA and Trikha D N (2007) Response of pre-cast reinforced 441 composite sandwich panels to axial loading. Construction and Building Materials, 21(5): $442 \quad 677-685$.

443 Benayoune A, Samad A A Abdul, Trikha D N, Ali A A A and Ashrabov A A (2006) Structural 444 behavior of eccentrically loaded precast sandwich panels. Construction and Building $445 \quad$ Materials, 20(1): 713-724.

446 Cao W, Zhang Y and Dong H (2015) Research and application on seismic energy-saving 447 structural system for rural buildings. Engineering Mechanics, 32(12):1-12.

448 Huang Q (2013) Research on seismic and energy-saving performance of new type 3D-building 449 in rural area. Ph.D. thesis, Sichuan University, China.

450 Huang Q, Liang D, Huang Y and Rui Y (2018) Numerical analysis on seismic performance of 451 loadbearing 3Dwalls. Journal of Southwest Jiaotong University,53 (5):983-988.

452 Huang Q, Xiong F and Zhou N(2014) Experimental research on seismic performance of new 453 type 3D-walls. Journal of Sichuan University,46(3):15-22.

454 Isabella G, Matteo C and Marcodi P (2015) Bending behaviour of Textile Reinforced Concrete 455 sandwich beams. Construction and Building Materials, 95: 675-685.

456 Janardhana M, Davis P R, Ravichandran S S, Prasad A M and Menon D. (2014) Calibration of 457 a hysteretic model for glass fiber reinforced gypsum wall panels. Earthquake Engineering $458 \quad$ and Engineering Vibration, 13(2): 347-355.

459 Ji G. (2018) The economic and feasibility analysis of gas and coal were used as fuel for making $460 \quad$ sintered brick. Tile, (8):40-44. 
461 Jia H, Zhang D, Zheng S Xie W and Pandey M D (2013) Local site effect on a high-pier railway 462 bridge under tridirectional spatial excitations: nonstationary stochastic analysis. Soil 463 Dynamics and Earthquake Engineering, 52:55-69.

464 Jiang X, Gu Y (2007) Restoring-Force Test of Fiber-Reinforced Plasterboard with Concrete 465 Core Column. Journal of Tianjin University,40(5):542-547.

466 Kabir M (2005) Structural performance of 3D sandwich wallboards under shear and flexural 467 loading. Scientia Iranica,12(1):402-408.

468 Liu K. (2013) Shear Strength of Concrete and Gypsum Composite Walls. Applied Mechanics 469 and Materials, (368-370): 976-983.

470 Liu Y(2007) An experimental study on seismic behavior of CS wallboard structure, Master 471 thesis, Tianjin University, China.

472 Magliulo G, Petrone C, Capozzi V, Maddaloni G, Lopez P, Manfredi G. (2014) Seismic 473 performance evaluation of plasterboard partitions via shake table tests. Bulletin of $474 \quad$ Earthquake Engineering, 12: 1657-1677.

475 Mohamad N and Hassan N (2013) The structural performance of precast lightweight foam 476 concrete sandwich panel with single and double shear truss connectors subjected to axial 477 load. Advanced Materials Research, 638(1): 2746-2751.

478 Mohamad N, Mahdi and Muhammad H. (2011) Testing of precast lightweight foamed concrete 479 sandwich panel with single and double symmetrical shear truss connectors under eccentric $480 \quad$ loading. Advanced Materials Research, 336(2): 1107-1116.

481 National standard of the People's Republic of China: GB50011-2010 (2010) Code for design of 482 buildings.

483 Ramachandra M V, Ramesh K and Smitha G (2014) Structural performance of precast and cast484 in-situ ultra high strength concrete sandwich panel. Tech Science Press CMC44(1):59-72. 
485 Retamales R, Davies R, Mosqueda G and Filiatrault A (2013) Experimental seismic fragility of 486 cold-formed steel framed gypsum partition walls. Journal of Structural Engineering, 139: $487 \quad 1285-1293$.

488 Rodrigo L, Joaquim B, Isabel B and Miguel A (2013) Development of sandwich panels 489 combining fibre reinforced concrete layers and fibre reinforced polymer connectors. Part I: $490 \quad$ conception and pull-out tests. Composite Structures, 105(8): 446-459.

491 Smitha G V, Ramesh K and Harishkumar S (2014) Pre-fabricated sandwich panels using cold492 formed steel and textile reinforced concrete. Construction and Building Materials, 64: 5449359.

494 Tian J and Su J (2006)The basic measures to mitigate earthquake disaster in rural area. 495 Construction Quality(11):15-17.

496 Waiel M and Faruk K (2009) Behavior of single-story lightweight panel building under lateral 497 loads. Journal of earthquake engineering13(1):100-107.

498 Wang $\mathrm{Y}(2015)$ Whole life cycle carbon emissions research of industrialized precast 499 construction. Ph.D. thesis, Southeast University, China.

500 Wu Y F and Dare M P (2006) Flexural and shear strength of composite lintels in glass fiber 501 reinforced gypsum wall constructions. Journal of Materials in Civil Engineering, 18: 415502423. 